\title{
Disease Risk, Spatial Patterns, and Incidence-Severity Relationships of Fusarium Head Blight in No-till Spring Wheat Following Maize or Soybean
}

Pierri Spolti, Departamento de Fitossanidade, Universidade Federal do Rio Grande do Sul, Porto Alegre, RS 91540000; Denis A. Shah, Department of Plant Pathology, Kansas State University, Manhattan, KS 66506; José Maurício C. Fernandes, Centro Nacional de Pesquisa de Trigo, Empresa Brasileira de Pesquisa Agropecuária - Embrapa, Passo Fundo, RS 99001970; Gary C. Bergstrom, Department of Plant Pathology and Plant-Microbe Biology, Cornell University, Ithaca, NY 14853; and Emerson M. Del Ponte, Departamento de Fitossanidade, Universidade Federal do Rio Grande do Sul, Porto Alegre, RS 91540000

\begin{abstract}
Spolti, P., Shah, D. A., Fernandes, J. M. C., Bergstrom, G. C., and Del Ponte, E. M. 2015. Disease risk, spatial patterns, and incidence-severity relationships of Fusarium head blight in no-till spring wheat following maize or soybean. Plant Dis. 99:1360-1366.

The first large-scale survey of Fusarium head blight (FHB) in commercial wheat fields in southern Brazil was conducted over three years (2009 to 2011). The objectives were to: (i) evaluate whether increased FHB risk is associated with within-field maize residue; (ii) determine the spatial pattern of FHB incidence; and (iii) quantify the relationship between FHB incidence and severity. FHB was assessed in a total of 160 fields between early milk and dough. Incidence ranged from 1.0 to $89.9 \%$ (median $=25 \%$ ) and severity from 0.02 to $18.6 \%$ (median $=$ $1.3 \%)$. FHB risk was neither lower nor higher in wheat following maize than in wheat following soybean. Only $18 \%$ of fields were

classified as having aggregated patterns of FHB-symptomatic spikes. A binary power law description of the variances was consistent with an overall random pattern of the disease. These results conform with the hypothesis that FHB epidemics in southern Brazil are driven by sufficient atmospherically-transported inoculum from regional sources. The incidence-severity relationship was coherent across growing season, growth stage, and previous crop; one common fitted curve described the relationship across all observations. Estimating severity from incidence may be useful in reducing the workload in epidemiological surveys.
\end{abstract}

Members of the Fusarium graminearum species complex (FGSC) are the main cause of Fusarium head blight (FHB), a devastating disease of wheat and barley worldwide (Gilbert and Haber 2013; McMullen et al. 2012). FHB is of concern because mycotoxins produced during pathogenesis, particularly the trichothecenes deoxynivalenol (DON) and nivalenol (NIV), may be found at levels considered unsafe in grain destined for human or animal consumption (Del Ponte et al. 2012; McMullen et al. 2012). Within the FGSC, $F$. graminearum sensu stricto (hereafter $F$. graminearum), particularly the DON or 15-acetyldeoxynivalenol (ADON) chemotypes, appears to be the dominant species associated with FHB in wheat across the Americas (Del Ponte et al. 2015; Ramirez et al. 2007; Schmale et al. 2011; Umpiérrez-Failache et al. 2013), whereas in some European countries other Fusaria such as $F$. culmorum, $F$. avenaceum, and $F$. poae outside the FGSC are also associated with FHB (Xu et al. 2005). In Brazil, Argentina, and Uruguay, six other FGSC members ( $F$. asiaticum, $F$. austroamericanum, $F$. cortaderiae, $F$. boothii, F. brasilicum, and $F$. meridionale), including some NIV-producers (Aoki et al. 2012), also cause FHB in wheat and barley, albeit at a much lower frequency than $F$. graminearum (Alvarez et al. 2011; Astolfi et al. 2011, 2012; Del Ponte et al. 2015; UmpiérrezFailache et al. 2013).

In the temperate regions of North America and Europe, large amounts of maize residue are an important risk factor for FHB epidemics, because the relatively lower residue decomposition rates

Current address of P. Spolti: Monsanto do Brasil, Morrinhos, GO, Brazil 75650-000.

Current address of E. M. Del Ponte: Departamento de Fitopatologia, Universidade Federal de Viçosa, Viçosa, MG, Brazil 36570-900.

Corresponding author: E. M. Del Ponte; E-mail: delponte@ufv.br

Accepted for publication 22 February 2015.

http://dx.doi.org/10.1094/PDIS-09-14-0944-RE

(C) 2015 The American Phytopathological Society (compared with the subtropics) prolong the period over which infested residue can serve as an inoculum source (Fernandez and Fernandes 1990; Landschoot et al. 2013; Schaafsma et al. 2005). Ascospores of the fungus from a known source may be dispersed at least $300 \mathrm{~m}$ above the canopy and infect wheat several kilometers away (Prussin et al. 2014; Schmale et al. 2012). In Brazil, viable FHB inoculum is found in the air above wheat fields yearround, peaking during flowering (Del Ponte et al. 2005; Nicolau and Fernandes 2012; Reis 1988). However, little is known about the relative importance of previous crop residue, typically soybean or maize, to FHB epidemics in subtropical no-till cropping systems.

Spatial patterns of FHB-infected wheat spikes provide an indirect measure of the relative contribution of within-field versus external inoculum sources to FHB epidemics (Del Ponte et al. 2003). In the United States, FHB-infected spikes occur mainly at random throughout a field (Del Ponte et al. 2003; El-Allaf et al. 2002; Wilhelm and Jones 2005). Aggregation of FHB-infected wheat spikes is more likely in the presence of high amounts of withinfield maize residue or high disease incidence (El-Allaf et al. 2002; Del Ponte et al. 2003).

Much effort has been devoted to studying the empirical relationship between disease intensities assessed at different hierarchical scales (McRoberts et al. 2003; Paul et al. 2005; Xu et al. 2004), partly with the aim of predicting either severity or incidence at a lower scale from more easily measured disease incidence at a higher scale. Empirical FHB incidence-severity $(I-S)$ relationships have been constructed for winter wheat in the United States (Groth et al. 1999; Paul et al. 2005) and Europe (Xu et al. 2004).

FHB spatial patterns and $I-S$ relationships have not as yet been studied in wheat grown under the conservation tillage systems used in the subtropical climate of southern Brazil. In this article, we hypothesize that abundant airborne inoculum in southern Brazil overshadows the effect of within-field inoculum sources, resulting in no significant increase in FHB risk in fields with maize residue and giving rise to a predominantly random pattern of diseased spikes. The objectives of the 3-year survey of commercial 
wheat fields in southern Brazil were to (i) evaluate whether the presence of within-field maize residue was associated with higher levels of FHB compared with soybean residues, (ii) determine the spatial pattern of FHB incidence at the within-field scale and explore differences in incidence across fields, and (iii) quantify the relationship between FHB incidence and severity.

\section{Materials and Methods}

Field information. FHB was assessed in 160 commercial spring-wheat fields in the predominantly no-till cereal-growing region of Rio Grande do Sul State, Brazil, during the $2009\left(n_{2009}=\right.$ 51 fields), $2010\left(n_{2010}=49\right)$, and $2011\left(n_{2011}=60\right)$ growing seasons between early milk and dough (Fig. 1). Fields were assessed during these developmental stages to avert confounding of disease symptoms with natural senescence. Latitude and longitude (taken at the field corner next to the road), developmental stage (sensu Zadoks et al. 1974), and previous crop (based on visible withinfield residues) were recorded for each field. Wheat cultivar, cropping practices, fungicide treatments, and other such metadata were not available.

Disease assessments. Wheat spikes were sampled at 20 sites along $\mathrm{W}$-shaped transects within each field. The sampling unit (su) at each site was a 1-m-long row, from which 10 contiguous spikes were removed and placed in labeled paper bags. Within $8 \mathrm{~h}$ postcollection, each spike was visually assessed individually for the proportion of spikelets with visible FHB symptoms. For each field, incidence $(I)$ was calculated as the proportion of diseased spikes out of all sampled spikes, and severity $(S)$ as the mean proportion of diseased spikelets per spike. These measurements (both on a 0 to 1 scale) therefore represented two different hierarchical levels: $I$ was the FHB intensity at the field level and $S$ was the FHB intensity at the spike level (Paul et al. 2005).

Field-specific factors and FHB. Logistic regression models were fit to $I$ and to $S$ data, with growing season, previous crop, growth stage, and latitude and longitude as predictors. A quasibinomial error distribution was used to handle apparent overdispersion. Of the 160 wheat fields that were evaluated, 56 followed maize, 103 followed soybean, and one followed potato. This latter single observation was removed before fitting the models. Growing season (2009, 2010, 2011), previous crop (maize, soybean), and growth stage (early milk, late milk, dough) were factor variables; latitude and longitude were continuous. Parameter estimates were assessed for significance (i.e., whether they differed from zero) by $95 \%$ profile likelihood confidence intervals.

In a different approach, observations were categorized as epidemic (1) or nonepidemic (0) by dichotomizing $S$ on a cut-point $x$ :

$$
\mathrm{fhb}_{i}=\left\{\begin{array}{lll}
0 & \text { if } & S_{i}<x \\
1 & \text { if } & S_{i} \geq x
\end{array}\right.
$$

which is the same strategy used in another study (Shah et al. 2013). Three values of $x$ were used ( $x=0.01,0.025$, and 0.04$)$, corresponding to about the 40th, 70th, and 80th quantiles of the empirical severity data. That is, these three cut points corresponded to roughly classifying 60,30 , and $20 \%$ of observations as epidemics.

For each cut point, a two-way cross tabulation (epidemicnonepidemic versus maize-soybean) was constructed. A Bayesian version of an unconditional test for the contingency table (Gelman et al. 2014) assessed whether the proportion of FHB epidemics in wheat fields following maize was lower, the same as, or higher than the proportion of FHB epidemics in wheat fields following soybean. The proportions of wheat fields with FHB epidemics following maize $\left(\theta_{1}\right)$ or soybean $\left(\theta_{2}\right)$ were modeled as binomial distributions, with simple uniform priors on the proportions [i.e., $\theta_{1} \sim$ $U(0,1)$ and $\left.\theta_{2} \sim U(0,1)\right]$. The posterior density of the difference between the proportions, $\delta=\theta_{1}-\theta_{2}$, was estimated via Monte Carlo simulation.

Spatial analysis. FHB within fields. The tendency for FHBsymptomatic spikes to occur in clusters within individual fields was examined using probability-based measures of spatial aggregation. For each field, the index of dispersion $[D]$ (Fisher 1925) was estimated from the su-level incidence data (i.e., the proportion of FHB-symptomatic spikes per su). A value of $D>1$ suggests that an aggregated pattern of FHB-symptomatic spikes in that field, which can be formally assessed as $(N-1) D$ has a $\chi^{2}$ distribution (Pielou 1977). The $C(\alpha)$ test (Madden and Hughes 1995) was also used, assuming that the su-level incidence values were described by the beta-binomial distribution. A field's FHB spatial pattern was characterized as "aggregated" if the index of dispersion and $\mathrm{C}(\alpha)$ tests were statistically significant (at $P<0.05$ ), and as "random" otherwise. The tendency to aggregation was also investigated by calculating the intracluster correlation coefficient $(\rho)$,

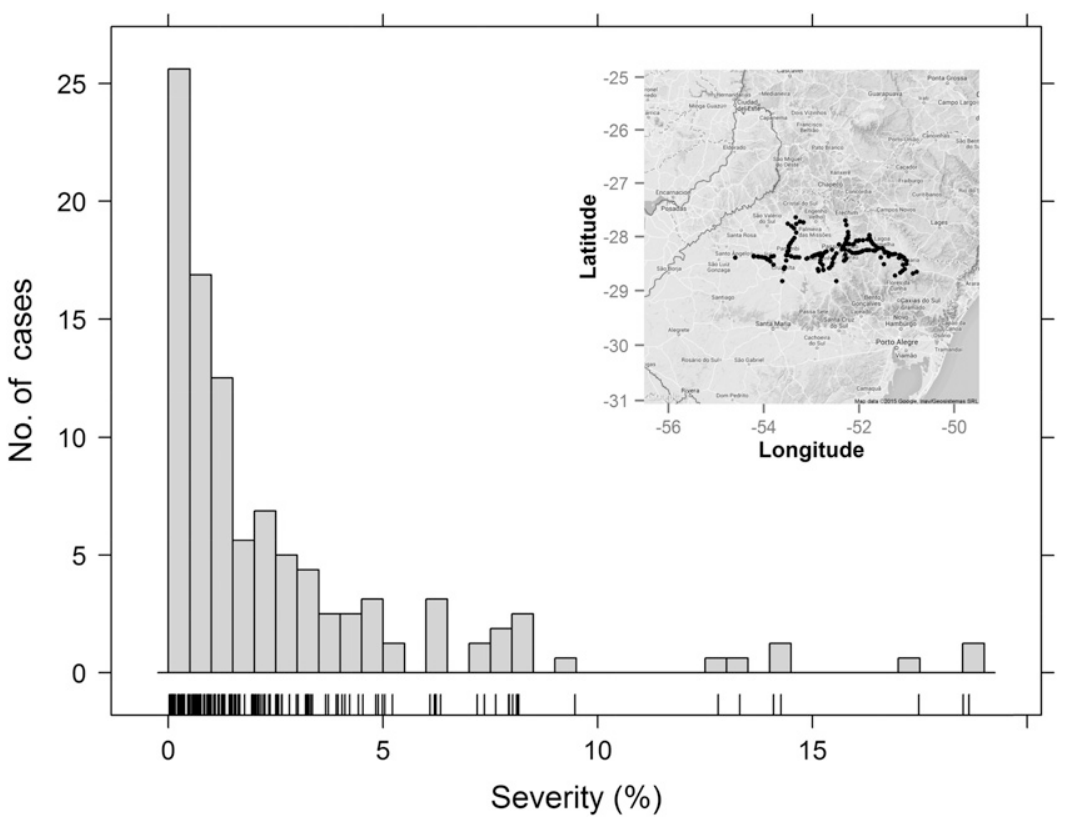

Fig. 1. Frequency distribution of Fusarium head blight severity in 160 commercial spring-wheat fields surveyed in 2009, 2010, or 2011 in Rio Grande do Sul State, Brazil. Inset: the geographical locations of the fields. 
again under the assumption of a beta-binomial model for the su-level values. A test of equality of proportions was used to determine if the proportions of aggregated and random fields differed by growing season, growth stage at sampling, or previous crop (maize or soybean) (Newcombe 1998).

The index of dispersion and $\mathrm{C}(\alpha)$ tests are useful for addressing the hypothesis of aggregated FHB-symptomatic spikes one field at a time. An alternative summary of su-level clustering, this time over all fields, is the binary power law (Hughes and Madden 1992). It empirically summarizes a relationship between variances:

$$
S_{\mathrm{obs}}^{2}=a \times\left(S_{\mathrm{bin}}^{2}\right)^{b}
$$

where for each field $S_{\text {obs }}^{2}$ and $S_{\text {bin }}^{2}$ are, respectively, the observed and theoretical binomial variances in the proportion of FHBsymptomatic spikes per su; the parameters $a$ and $b$ are determined by least-squares fitting of a linearized version of Equation 2 [log $\left.\left(S_{\text {obs }}^{2}\right)=\log a+b \times \log \left(S_{\text {bin }}^{2}\right)\right]$. Equation 2 in its linearized form was fit with separate slopes and intercepts for the categorical variables (growing season, growth stage, and previous crop). Likelihood
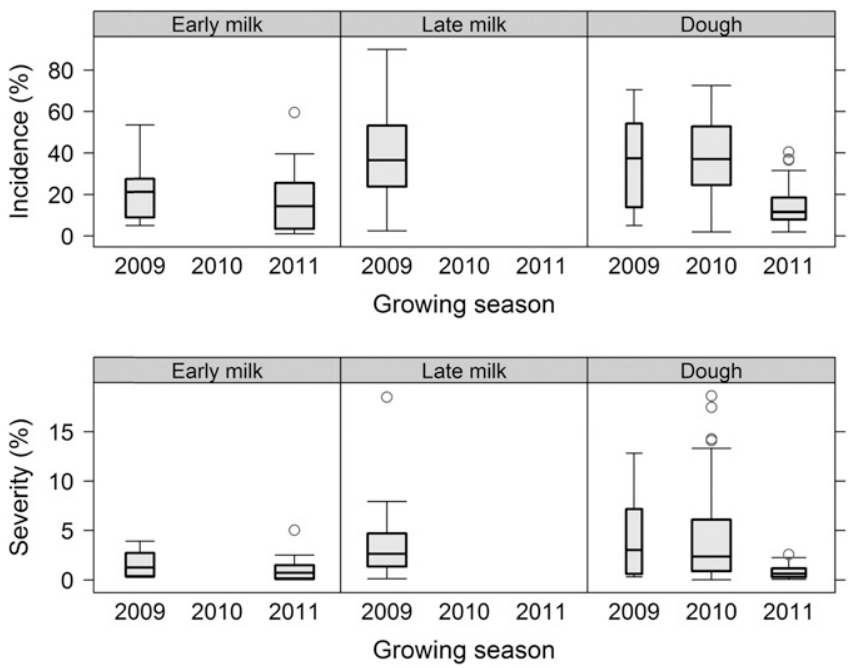

Fig. 2. Summaries of Fusarium head blight incidence and severity by growing season and growth stage at the time of disease assessment. Bar widths are proportional to the number of fields represented.

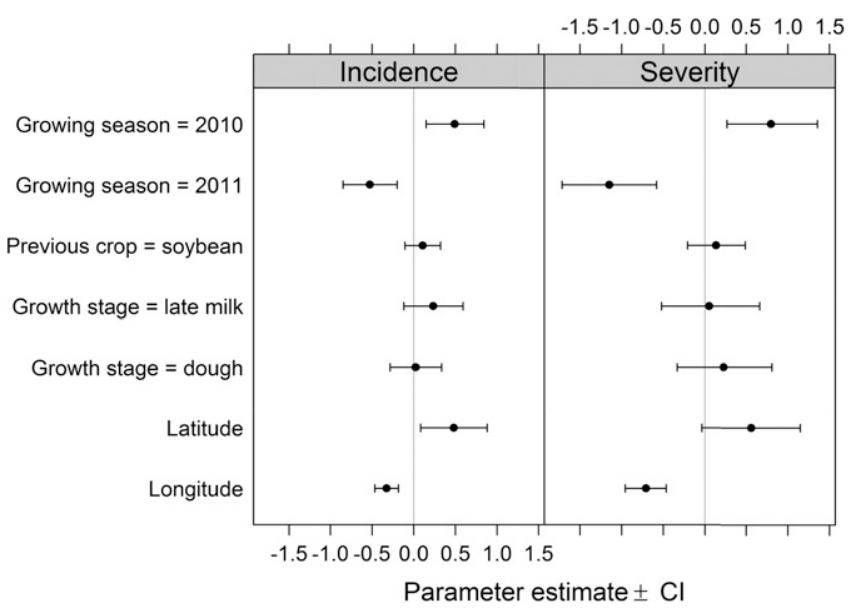

Fig. 3. Logistic regression parameter estimates for models of Fusarium head blight incidence and severity as a function of growing season, previous crop, growth stage, and field location. Growing season $=2009$, previous crop $=$ maize, and growth stage $=$ early milk were set as the baseline categories for these categorical variables. The $95 \%$ confidence intervals $(\mathrm{Cl})$ are shown for each point estimate. ratio tests (LRTs) were used to test whether the data supported different intercepts or slopes.

FHB across fields. The wheat fields surveyed were pseudorandomly selected, in that they were intentionally close to roadways and about 5 to $20 \mathrm{~km}$ apart (Fig. 1 inset), allowing for easy access and reduced travel time across several hundred kilometers. Because of this bias, we refrained from using contemporary spatial point pattern analyses of the geo-referenced FHB incidence per field. Instead, a graphical approach was used to visualize the differences in FHB incidence as a function of distance between fields. The basic idea is as follows: if proximal fields had experienced similar epidemic conditions, then the difference in FHB incidence ought to be smaller than between fields separated by a greater distance. The geodesic distance between all pairs of fields in a given year was estimated, along with the difference in FHB incidence between each pair of fields. For example, the 49 fields sampled in 2010 gave rise to $(49 * 49$ $49) / 2=1,176$ pairwise combinations. This is too many points to represent effectively in a traditional scatterplot because features may be hid by the sheer number of overlapping points. Therefore, a smoothed density representation of the scatterplot was created to visualize pairwise differences in FHB incidence versus distance between fields.

Incidence-severity relationship. Complementary log-log models (McRoberts et al. 2003; Paul et al. 2005) were fit to the $(I, S)$ data:

$$
\begin{aligned}
& \operatorname{CLL}(S)=\alpha+\beta \operatorname{CLL}(I) \\
& \operatorname{CLL}(S)=\alpha_{i}+\beta_{i} \operatorname{CLL}(I)
\end{aligned}
$$

where $\alpha$ and $\beta$ are model parameters and $\operatorname{CLL}(\bullet)$ is the complementary $\log -\log$ transformation of $I$ (i.e., $\ln [-\ln (1-I)]$ ), and of $S$ (i.e., $\ln [-\ln (1-S)]$ ). Equation 3 a represented a single model describing all observations, whereas Equation $3 \mathrm{~b}$ allowed for potentially distinct $\alpha_{i}$ and $\beta_{i}$ parameters representing different levels of growing season, growth stage, or previous crop (maize or soybean).

Equations $3 \mathrm{a}$ and $3 \mathrm{~b}$ were fit using a complementary log-log link function which assumes that errors have a reverse extreme value distribution (Hilbe 2009). Because Equations 3a and 3b were nested, LRTs were used to assess whether different $\alpha$ or $\beta$ were supported by the data. Model fit was evaluated by examining scatterplots of $\operatorname{CLL}(S)$ versus CLL $(I)$ superimposed with fitted equations, McFadden's pseudo $\mathrm{R}^{2}$ (McFadden 1974), and the Pearson correlation between actual and predicted severity values (after back-transformation). Predicted $\operatorname{CLL}(\hat{S})$ values and the associated $99 \%$ prediction interval endpoints were back-transformed to get $\hat{S}$ and $99 \%$ prediction intervals on the original measurement scale.

\section{Results}

Field information. More than half of the fields (59.4\%) were in the dough stages (Zadoks 83 to 87) when sampled (Fig. 2). The remainder (21.2 and 19.4\%) were either in the early milk (Zadoks 73) or late milk (Zadoks 77) stages, respectively. As described above, almost twice as many fields followed soybean than maize as the previous crop.

Disease assessments. $I$ ranged from 1.0 to $89.9 \%$, and $S$ from 0.02 to $18.6 \%$ (Fig. 1), across all 160 fields. $I$ and $S$ in the 2009 and 2010 growing seasons were higher than in 2011 . Mean $I$ was $33.9 \%$ in 2009 and $36.6 \%$ in 2010 , but was $15.3 \%$ in 2011 . Likewise, mean $S$ was $3.3 \%$ in 2009 and $4.2 \%$ in 2010, but was $0.9 \%$ in 2011 (Fig. 2). Overall, the distributions of $I$ and $S$ were both positively skewed, more so for $S$ (Fig. 1), for which the mean was $2.7 \%$ and the median $1.3 \%$.

Field-specific factors and FHB. Logistic regression models fit to $I$ and $S$ with growing season, previous crop, growth stage, and latitude and longitude as predictors indicated no increased risk of FHB in wheat following maize compared with wheat following soybean, because the confidence intervals for the parameters representing previous crop included zero (Fig. 3). These simple models did 
indicate a significant spatial component, which is addressed later in this article.

Posterior densities of $\delta$, stemming from the creation of two-way contingency tables based on Equation 1 and cut-points $x=0.01$, 0.025 , or 0.04 , all supported the hypothesis of no difference between the proportion of wheat fields which experienced FHB epidemics following maize and the proportion of wheat fields which experienced FHB epidemics following soybean. With $x=0.01$, there was a $95 \%$ chance that $\delta$ was in the range [-0.307, 0.002]. With $x=0.025$ that range was $[-0.253,0.034]$ (Fig. 4), and with $x=0.04$ it was $[-0.187,0.063]$.

Spatial analysis. FHB within fields. The binomial distribution sufficiently described the intracluster variability in the proportion of FHB-symptomatic spikes across all incidence values. Only $18 \%$ of fields were classified, by both the index of dispersion and $\mathrm{C}(\alpha)$ tests, as having aggregated patterns of FHB-symptomatic spikes. Two outliers $\left(S_{\text {obs }}^{2}>0.10\right)$ were removed before proceeding with the binary power law analysis. For the binary power law, there was no support for separate slopes or intercepts for season, growth stage, or previous crop, because the resulting decrease in deviance was not significant by having these extra parameters (Table 1). Figure 5 shows the fitted equation. The point estimate for $a$ was 1.05 (95\% CI of 0.91 to 1.22 ); for $b$ the point estimate was 1.00 (95\% CI of 0.93 to 1.08). Hence, neither $a$ nor $b$ were significantly different from 1 . The intracluster correlation coefficient $(\rho)$ was at or close to zero for the majority of the individual fields, with fields identified as having clusters of FHB-symptomatic spikes at the upper end of the spectrum of $\rho$ values (Fig. 6). The proportion of fields with aggregated patterns of FHB-symptomatic spikes was not different among growing seasons

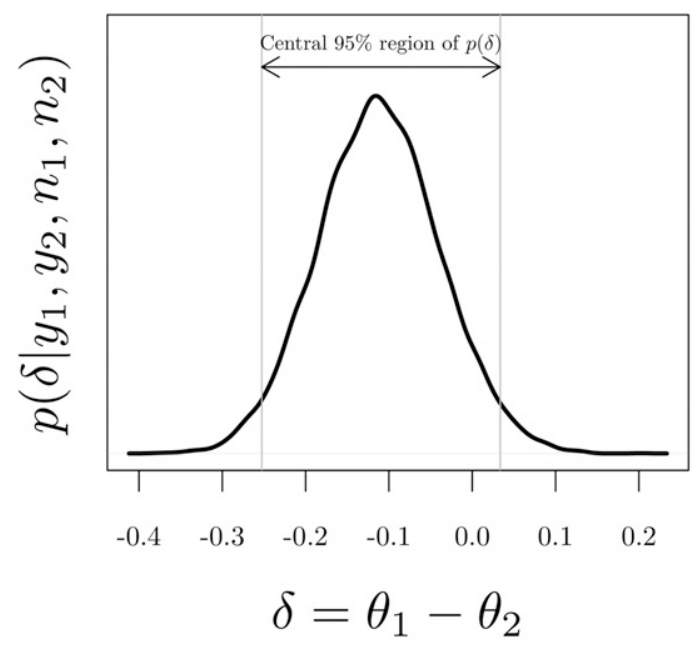

Fig. 4. The posterior distribution of $\delta$, the difference in the proportion of wheat fields following maize which experienced Fusarium head blight epidemics $\left(\theta_{1}\right)$ and the proportion of wheat fields following soybean which experienced Fusarium head blight epidemics $\left(\theta_{2}\right)$. The proportions $\theta_{1}$ and $\theta_{2}$, and hence $\delta$, are conditional on the respective number of fields which experienced epidemics $\left(y_{1}, y_{2}\right)$ out of the total number of fields observed $\left(n_{1}, n_{2}\right)$. An epidemic was defined as severity $\geq 2.5 \%$. The vertical gray lines are the boundaries of the central $95 \%$ region of $p(\delta)$.
$(P=0.117)$, growth stages $(P=0.936)$, or between fields with maize or soybean as the previous crop $(P=0.461)$.

FHB across fields. In 2010, sampled fields were confined to a narrower geographic region than in the other two years, in that the maximum distance between fields in 2010 was $120 \mathrm{~km}$ less than it was in 2009 and 2011 (Fig. 7). In each panel of Figure 7, regions with higher densities of data points are darker in color, and there is an increase in darkness as one moves toward the bottom left corner. Therefore, fields which were closer geographically were more likely to have similar FHB incidence levels than fields separated by greater distances.

Incidence-severity relationship. Decreases in model deviance, by having separate intercept and/or slope parameters in Equation $3 \mathrm{~b}$ for growing season, growth stage, or previous crop, were not statistically significant (Table 2). Hence, one common slope and intercept were sufficient to describe the $I-S$ relationship across all 160 observations (Fig. 8). The fitted version of Equation 3a was

$$
\operatorname{CLL}(S)=-2.53+1.17 \operatorname{CLL}(I)
$$

where the $95 \%$ confidence intervals for $\alpha$ and $\beta$ were $(-2.66,-2.40)$ and $(1.03,1.32)$, respectively. McFadden's pseudo $\mathrm{R}^{2}$ for the fitted model was 0.73 , and the Pearson correlation coefficient between $S$ and $\hat{S}$ was $0.80 . S$ was more precisely estimated (narrower confidence intervals) at lower $I$.

\section{Discussion}

This article reports on the first large-scale survey of Fusarium head blight in commercial wheat ever done in Rio Grande do Sul State,

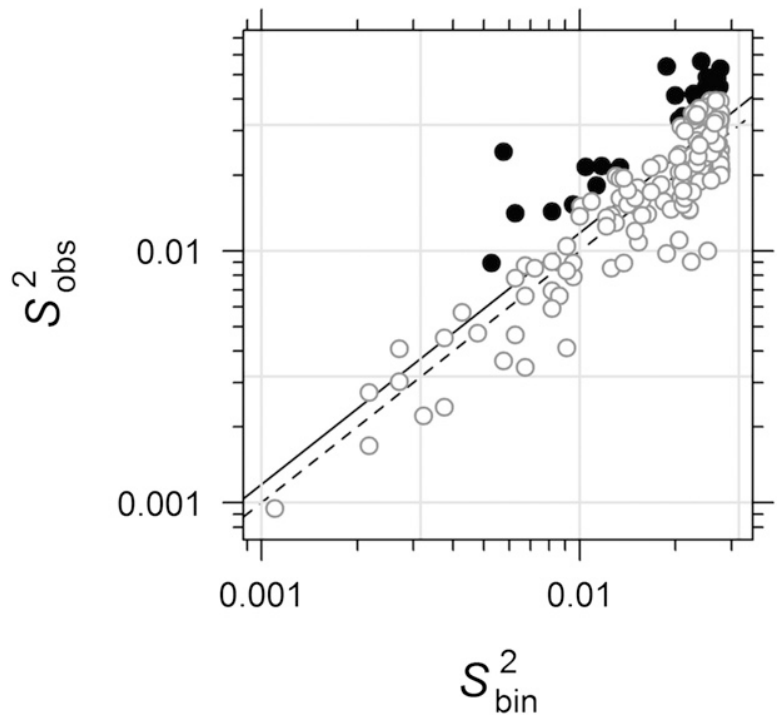

Fig. 5. Relationship between the observed variance $\left(S_{\mathrm{obs}}^{2}\right)$ and the theoretical binomial variance $\left(S_{\text {bin }}^{2}\right)$ in the proportion of wheat spikes per sampling unit with Fusarium head blight. The solid line is the binary power law relationship fitted to the data. The dashed line references $S_{\text {obs }}^{2}=S_{\text {bin }}^{2}$. Fields for which the index of dispersion and $C(\alpha)$ tests were significant $(P<0.05)$ are shown as filled black circles, whereas the other fields are represented by open gray circles.

Table 1. Likelihood ratio tests comparing binary power law models ${ }^{\mathrm{a}}$ of the variances in the proportion of spikes with Fusarium head blight

\begin{tabular}{|c|c|c|c|c|c|c|}
\hline \multirow[b]{2}{*}{ Added factor } & \multicolumn{2}{|c|}{ Different intercept $(a)$} & \multicolumn{2}{|c|}{ Different slope (b) } & \multicolumn{2}{|c|}{ Different $a$ and $b$} \\
\hline & $\Delta$ Deviance $^{\mathbf{b}}$ & $P^{\mathrm{c}}$ & $\Delta$ Deviance & $P$ & $\Delta$ Deviance & $P$ \\
\hline Growing season & 0.067 & 0.269 & 0.060 & 0.308 & 0.109 & 0.371 \\
\hline Growth stage & 0.022 & 0.658 & 0.027 & 0.598 & 0.062 & 0.664 \\
\hline Previous crop & 0.036 & 0.240 & 0.034 & 0.251 & 0.036 & 0.503 \\
\hline
\end{tabular}

a See Equation 2.

b The change in deviance upon allowing separate slope or intercept parameters for the different levels of the given factor.

c $P$ value for the likelihood ratio test, in which the model with separate slope and/or intercept for the given factor is compared with the simplest model which has a single slope and intercept for all the data. 
Brazil, a region typified by a subtropical climate and a history ( $>20$ years) of no-till cultivation practices. During the 3 -year period covered by the survey, FHB severity was generally low, because $S$ was less than $3 \%$ in about $70 \%$ of assessed fields. It is possible that $S$ could have further increased between the time of disease assessment and harvest, although we did not find any evidence that $I$ or $S$ were any higher in fields evaluated during dough compared with fields evaluated during the milk stages. Rather, variability in FHB intensity was associated with growing season and locality, which was consistent with FHB being a weather-driven disease (De Wolf et al. 2003; Shah et al. 2014).

The positive skewness in the distribution of field-level FHB severity (i.e., mean $>$ median because of a few fields with relatively high disease) is also seen in the distribution of severity values recorded over several years in the United States (see Figure 4 in Shah et al. 2013). The similarities in the severity distributions is intriguing, given that the data being reported in the current article were gathered from commercial fields, whereas the data in Shah et al. (2013) were gathered from a coordinated network of unsprayed small-plot trials. Together, these data are consistent with the observed sporadic nature of FHB outbreaks.

However, the severity distribution for the survey data reported in the current article was much narrower in range (0.02 to $18.6 \%)$ compared with the United States data (0 to $86 \%$ ). This was the main reason why cut-points much lower than $10 \%$ were used in the current article to categorize observations as epidemic or nonepidemic (De Wolf et al. 2003; Shah et al. 2013, 2014). There could be several reasons for the differences in the severity distributions between southern Brazil and the United States. The data reported in the current article covered a 3-year period, whereas the data reported in Shah et al. (2013) were collected over 16 years; the time period in the latter is likely to have experienced a wider set of FHB-conducive conditions compared with the 3-year interval of the survey. It appears overall environmental conditions across Rio Grande do Sul State were not highly conducive to FHB during the 2009 to 2011 survey years, particularly in 2011. In a survey of DON and NIV in commercial wheat grain produced in this same state from 2006 to 2008, more than $80 \%$ of the samples had mycotoxin levels less than $1 \mathrm{ppm}$ (Del Ponte et al. 2012). Therefore, FHB does not seem to have been a significant problem in Rio Grande do Sul State during the second half of the decade beginning with 2000 . Nonetheless, according to simulations, a series of epidemic years such as seen in the mid-1990s is probable depending on seasonal weather and decadal climate variability (Del Ponte et al. 2009).

Besides the local weather factor, low FHB intensities could have also been influenced by cultivar resistance and management factors, particularly fungicide applications (Spolti et al. 2013). Such metadata were not available for the current survey, but ought to be included in any subsequent observational study. Growers in southern Brazil rely on one or two fungicide sprays during or after flowering to reduce FHB (Mehta 2014). Common strategies include using a triazole fungicide alone or mixed with a strobilurin fungicide (for foliar disease control), and have been shown to reduce FHB by $70 \%$ on average. Control is superior when two sprays are used instead of one, according to field experiments (Spolti et al. 2013).

In North America and Europe, large amounts of within-field maize residue is considered a FHB risk factor, and hence rotating wheat and maize with nonhost crops is recommended for managing FHB (Dill-Macky and Jones 2000; Landschoot et al. 2013; Schaafsma et al. 2005). We did not quantify surface residue, but no-till systems typically leave at least $30 \%$ of the soil surface covered with residue (Lal 1997). However, the results shown in the current article do not support the contention that the risk of FHB was any higher in wheat following maize than in wheat following soybean under the no-till farming practices of southern Brazil. The scenario is similar in Argentina and Uruguay, where no-till is not consistently associated with increased FHB risk compared with conventional tillage (Lori et al. 2009; Pereyra and Dill-Macky 2008), leading these authors to conclude that weather is the major force behind FHB epidemics in those two countries. That conclusion is also supported by models from the United States showing

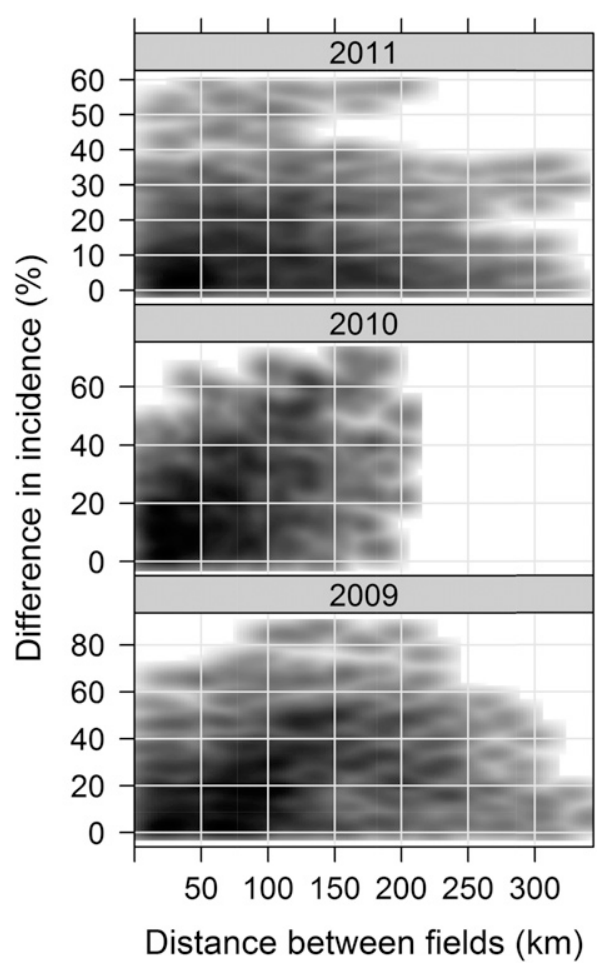

Fig. 7. Smoothed density representations of the pairwise distance between fields and the difference in Fusarium head blight incidence for each field pair. Darker areas within the plot have higher densities of points.

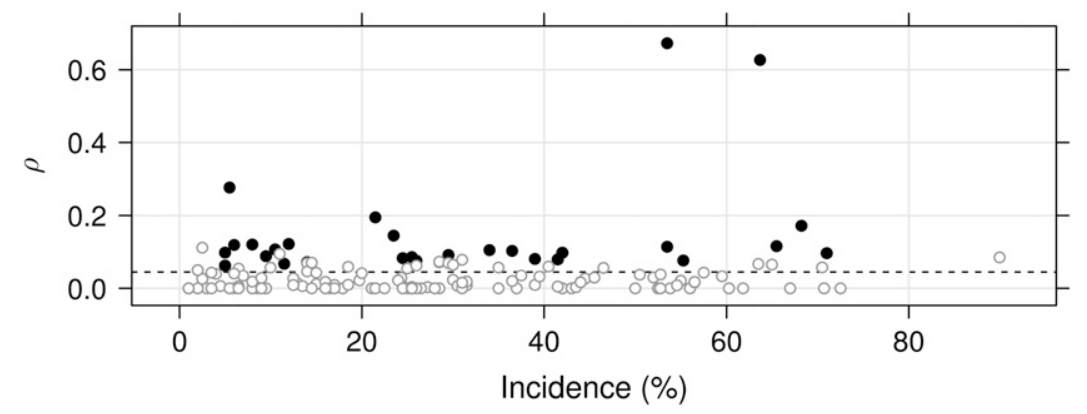

Fig. 6. Distribution of the intracluster correlation coefficient $(\rho)$ as a function of the mean proportion of spikes with Fusarium head blight. The dashed black line is at the overall mean value of $\rho$. Fields for which the index of dispersion and $\mathrm{C}(\alpha)$ tests were significant $(P<0.05)$ are shown as filled black circles, whereas the other fields are represented by open gray circles. 
that weather variables are relatively more important than maize residue in predicting FHB epidemics (Shah et al. 2014). The lack of association of within-field maize residue with a higher risk of FHB should not be taken to mean that within-field residue poses no risk. Rather, it appears that any risk due to within-field maize residue is overshadowed by the combined effects of a regional atmospheric inoculum pool and local weather. In southern Brazil, atmospheric inoculum may be derived from multiple sources, including year-round gramineous weeds (Mourelos et al. 2014; Reis 1990 ) and any field with maize residue. From an aerobiological perspective, FHB epidemics are initiated by spore deposition from the diffuse atmospheric pool (Schmale et al. 2005), which is more likely to occur during the night (Del Ponte et al. 2005). However, recent population biology data do call into question the overall significance of maize residue as a FHB risk factor (Boutigny et al. 2011). In southern Brazil, perithecia found on maize residue mainly belonged to $F$. meridionale and $F$. cortaderiae, whereas FHB-infected kernels from the same fields were colonized mainly by $F$. graminearum (Del Ponte et al. 2015).

Within-field spatial patterns of FHB can be used to make informed propositions as to the cause of such patterns, although they cannot directly link pattern to the underlying causative process. With FHB, random patterns of infected spikes are consistent with aerial deposition of spores onto spikes, whereas aggregated patterns are consistent with localized splash dispersal of infective propagules onto spikes from within-field sources. In the current study, only three out of 160 fields showed evidence of relatively strong aggregation $(D>$ 3) of FHB-symptomatic spikes, and the mainly random pattern is consistent with other data on FHB within-field patterns (Del Ponte et al. 2003; El-Allaf et al. 2002; Wilhelm and Jones 2005). Aggregated patterns of FHB are found in fields with either high amounts of maize residue on the soil surface or in fields in which FHB incidence was high (El-Allaf et al. 2002; Del Ponte et al. 2003). In our observational study, there was no evidence that within-field aggregation of infected spikes was associated with either maize or soybean residue, nor with higher FHB incidence. The predominantly random withinfield FHB patterns in southern Brazilian wheat is consistent with the proposition of a mainly atmospherically-based inoculum source. The observed randomness may be also due to a narrow window of infection which did not permit spike-to-spike spread (Fernando et al. 1997). Based on the fitted binary power law, the degree of spatial heterogeneity was constant at all incidence values, which is typical of monocyclic diseases (Seem 1984).

In our study, FHB incidence tended to be more similar in fields that were closer geographically. This finding agreed qualitatively with a statistically-oriented analysis of the heterogeneity of FHB incidence in Ohio wheat, in which significant spatial heterogeneity was found among counties and among fields within counties in each year (Kriss et al. 2012). Likely contributing factors to across-field heterogeneity were planting and anthesis dates, cultivar, and fertilizer use (Kriss et al. 2012). However, as in our case, these metadata were not known. Given that FHB epidemics are strongly driven by weather, we suggest that closer fields experienced more similar weather conditions, and perhaps were also similar in planting or anthesis date.

The fitted $I-S$ relationship in our study could be a useful timesaving option by estimating $S$ from $I$ in future FHB surveys of commercial wheat in southern Brazil, particularly if $I$ is kept to relatively low levels by cultivar resistance and fungicides sprays. However, as prediction intervals for $S$ increased with $I$, the relationship should be used cautiously (or not at all) in quantitative treatment evaluations (e.g., biological and chemical control experiments) if high $I$ is expected, or if $S$ is the more important measure of disease intensity.

In summary, predominantly random within-field patterns and no increase in FHB risk in wheat following maize conform with the hypothesis that FHB epidemics in subtropical no-till Brazilian wheat are driven by atmospherically-transported inoculum at a regional level. Estimates of $S$ from the more easily measured $I$ would reduce the workload in quantifying FHB in field surveys.

Table 2. Likelihood ratio tests comparing complementary log-log models ${ }^{\mathrm{a}}$ describing the relationship between Fusarium head blight severity and incidence

\begin{tabular}{|c|c|c|c|c|c|c|}
\hline \multirow[b]{2}{*}{ Added factor } & \multicolumn{2}{|c|}{ Different intercept $(\alpha)$} & \multicolumn{2}{|c|}{ Different slope $(\beta)$} & \multicolumn{2}{|c|}{ Different $\alpha$ and $\beta$} \\
\hline & $\Delta$ Deviance $^{b}$ & $P^{\mathrm{c}}$ & $\Delta$ Deviance & $P$ & $\Delta$ Deviance & $P$ \\
\hline Growing season & 0.091 & 0.014 & 0.011 & 0.620 & 0.127 & 0.017 \\
\hline Growth stage & 0.051 & 0.105 & 0.002 & 0.932 & 0.092 & 0.078 \\
\hline Previous crop & 0.054 & 0.028 & 0.019 & 0.197 & 0.054 & 0.090 \\
\hline
\end{tabular}

${ }^{a}$ See Equations $3 a$ and $3 b$.

b The change in deviance between fitted Equations $3 \mathrm{a}$ and $3 \mathrm{~b}$.

c $P$ value for a likelihood ratio test comparing the nested models represented by Equations $3 \mathrm{a}$ and $3 \mathrm{~b}$.
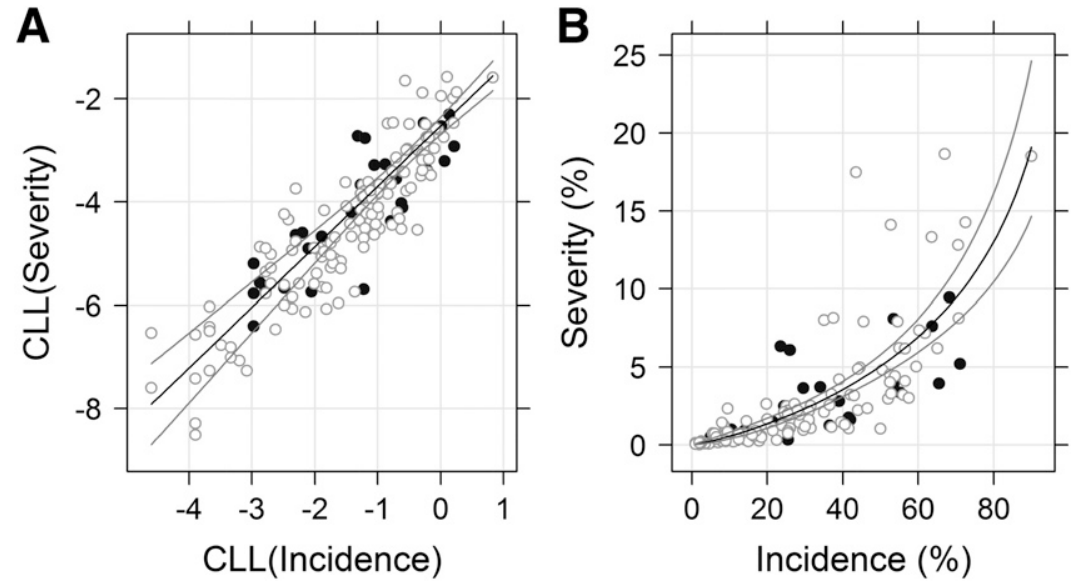

Fig. 8. Incidence-severity relationship for Fusarium head blight: (A) data points and fitted relationship (Equation 3a) on the complementary log-log scale; (B) data on the original measurement scale, with the fitted back-transformed equation. Solid black lines represent the fitted function. The gray lines give the $95 \%$ confidence interval limits. Fields for which the index of dispersion and $\mathrm{C}(\alpha)$ tests were significant $(P<0.05)$ are shown as filled black circles, whereas the other fields are represented by open gray circles. 


\section{Acknowledgments}

We thank the Programa de Pós-graduação em Fitotecnia of the Universidade Federal do Rio Grande do Sul (UFRGS) and Conselho Nacional de desenvolvimento Científico e Tecnológico $(\mathrm{CNPq})$ for providing a graduate scholarship to P. Spolti and a research fellowship to E. M. Del Ponte. The authors thank Serge Savary for his comments on an earlier draft of this article.

\section{Literature Cited}

Alvarez, C. L., Somma, S., Proctor, R. H., Stea, G., Mulè, G., Logrieco, A. F., Pinto, V. F., and Moretti, A. 2011. Genetic diversity in Fusarium graminearum from a major wheat-producing region of Argentina. Toxins 3: 1294-1309.

Aoki, T., Ward, T. J., Kistler, H. C., and O'Donnell, K. 2012. Systematics, phylogeny and trichothecene mycotoxin potential of Fusarium head blight cereal pathogens. Mycotoxins 62:91-102.

Astolfi, P., dos Santos, J., Schneider, L., Gomes, L. B., Silva, C. N., Tessmann, D. J., and Del Ponte, E. M. 2011. Molecular survey of trichothecene genotypes of Fusarium graminearum species complex from barley in southern Brazil. Int. J. Food Microbiol. 148:197-201.

Astolfi, P., Reynoso, M. M., Ramirez, M. L., Chulze, S. N., Alves, T. C. A., Tessmann, D. J., and Del Ponte, E. M. 2012. Genetic population structure and trichothecene genotypes of Fusarium graminearum isolated from wheat in southern Brazil. Plant Pathol. 61:289-295.

Boutigny, A. L., Ward, T. J., Van Coller, G. J., Flett, B., Lamprecht, S. C., O'Donnell, K., and Viljoen, A. 2011. Analysis of the Fusarium graminearum species complex from wheat, barley and maize in South Africa provides evidence of species-specific differences in host preference. Fungal Genet. Biol. 48:914-920.

De Wolf, E. D., Madden, L. V., and Lipps, P. E. 2003. Risk assessment models for wheat Fusarium Head Blight epidemics based on within-season weather data. Phytopathology 93:428-35.

Del Ponte, E. M., Fernandes, J. M. C., Pavan, W., and Baethgen, W. E. 2009. A model-based assessment of the impacts of climate variability on Fusarium head blight seasonal risk in southern Brazil. J. Phytopathol. 157:675-681.

Del Ponte, E. M., Fernandes, J. M. C., and Pierobom, C. R. 2005. Factors affecting density of airborne Gibberella zeae inoculum. Fitopatol. Bras. 30:55-60.

Del Ponte, E. M., Garda-Buffon, J., and Badiale-Furlong, E. 2012. Deoxynivalenol and nivalenol in commercial wheat grain related to Fusarium head blight epidemics in southern Brazil. Food Chem. 132:1087-1091.

Del Ponte, E. M., Shah, D. A., and Bergstrom, G. C. 2003. Spatial patterns of Fusarium head blight in New York wheat fields suggest role of airborne inoculum. Plant Health Progress 10.1094/PHP-2003-0418-01-RS.

Del Ponte, E. M., Spolti, P., Ward, T. J., Gomes, L. B., Nicolli, C. P., Kuhnem, P. R., Silva, C. N., and Tessmann, D. J. 2015. Regional and field-specific factors affect the composition of Fusarium head blight pathogens in subtropical no-till wheat agroecosystem of Brazil. Phytopathology 105:246-254

Dill-Macky, R., and Jones, R. K. 2000. The effect of previous crop residues and tillage on Fusarium head blight of wheat. Plant Dis. 84:71-76.

El-Allaf, S. M., Madden, L. V., and Lipps, P. E. 2002. Spatial aspects of Fusarium head blight epidemics on wheat in Ohio. Pages 148-150 in: Proc. 2002 Natl. Fusarium Head Blight Forum. U.S. Wheat and Barley Scab Initiative, East Lansing, MI.

Fernandez, M. R., and Fernandes, J. M. C. 1990. Survival of wheat pathogens in wheat and soybean residues under conservation tillage systems in southern and central Brazil. Can. J. Plant Pathol. 12:289-294.

Fernando, W. G. D., Paulitz, T. C., Seaman, W. L., Dutilleul, P., and Miller, J. D. 1997. Head blight gradients caused by Gibberella zeae from area sources of inoculum in wheat field plots. Phytopathology 87:414-421.

Fisher, R. A. 1925. Statistical Methods for Research Workers. Oliver and Boyd, London.

Gelman, A., Carlin, J. B., Stern, H. S., Dunson, D. B., Vehtari, A., and Rubin, D. B. 2014. Bayesian Data Analysis, 3rd Ed. CRC Press, Boca Raton, FL.

Gilbert, J., and Haber, S. 2013. Overview of some recent research developments in Fusarium head blight of wheat. Can. J. Plant Pathol. 35:149-174.

Groth, J. V., Ozmon, E. A., and Busch, R. H. 1999. Repeatability and relationship of incidence and severity measures of scab of wheat caused by Fusarium graminearum in inoculated nurseries. Plant Dis. 83:1033-1038.

Hilbe, J. 2009. Logistic Regression Models. CRC Press, Boca Raton, FL.

Hughes, G., and Madden, L. V. 1992. Aggregation and incidence of disease. Plant Pathol. 41:657-660.

Kriss, A. B., Paul, P. A., and Madden, L. V. 2012. Characterizing heterogeneity of disease incidence in a spatial hierarchy: A case study from a decade of observations of Fusarium head blight of wheat. Phytopathology 102:867-877.

Lal, R. 1997. Residue management, conservation tillage and soil restoration for mitigating greenhouse effect by $\mathrm{CO}_{2}$ enrichment. Soil Tillage Res. 43:81-107.

Landschoot, S., Audenaerta, K., Waegeman, W., De Baets, B., and Haesaert, G. 2013. Influence of maize-wheat rotation systems on Fusarium head blight infection and deoxynivalenol content in wheat under low versus high disease pressure. Crop Prot. 52:14-21.

Lori, G. A., Sistema, M. N., Sarandón, S. J., Rizzo, I., and Chidichimo, H. 2009. Fusarium head blight in wheat: impact of tillage and other agronomic practices under natural infection. Crop Prot. 28:495-502.
Madden, L. V., and Hughes, G. 1995. Plant disease incidence: Distributions, heterogeneity, and temporal analysis. Annu. Rev. Phytopathol. 33:529-564.

McFadden, D. 1974. Conditional logit analysis of qualitative choice behavior Pages 105-142 in: Frontiers in Econometrics. P. Zarembka, ed. Academic Press, New York.

McMullen, M., Bergstrom, G. C., De Wolf, E., Dill-Macky, R., Hershman, D., Shaner, G., and Van Sanford, D. V. 2012. A unified effort to fight an enemy of wheat and barley: Fusarium head blight. Plant Dis. 96:1712-1728.

McRoberts, N., Hughes, G., and Madden, L. V. 2003. The theoretical basis and practical application of relationships between different disease intensity measurements in plants. Ann. Appl. Biol. 142:191-211.

Mehta, Y. R. 2014. Wheat Diseases and Their Management. Springer, Switzerland

Mourelos, C. A., Malbrán, I., Balatti, P. A., Ghiringhelli, P. D., and Lori, G. A 2014. Gramineous and non-gramineous weed species as alternative hosts of Fusarium graminearum, causal agent of Fusarium head blight of wheat, in Argentina. Crop Prot. 65:100-104.

Newcombe, R. G. 1998. Interval estimation for the difference between independent proportions: Comparison of eleven methods. Stat. Med. 17:873-890.

Nicolau, M., and Fernandes, J. M. C. 2012. A predictive model for daily inoculum levels of Gibberella zeae in Passo Fundo, Brazil. Int. J. Agron. 10.1155/2012/795162.

Paul, P. A., El-Allaf, S. M., Lipps, P. E., and Madden, L. V. 2005. Relationships between incidence and severity of Fusarium head blight on winter wheat in Ohio. Phytopathology 95:1049-1060.

Pereyra, S. A., and Dill-Macky, R. 2008. Colonization of the residues of diverse plant species by Gibberella zeae and their contribution to Fusarium head blight inoculum. Plant Dis. 92:800-807.

Pielou, E. C. 1977. Mathematical Ecology. Wiley, NY.

Prussin, A. J., II, Li, Q., Malla, R., Ross, S. D., and Schmale, D. G., III. 2014 Monitoring the long-distance transport of Fusarium graminearum from fieldscale sources of inoculum. Plant Dis. 98:504-511.

Ramirez, M. L., Reynoso, M. M., Farnochi, M. C., Torres, A. M., Leslie, J. F., and Chulze, S. 2007. Population genetic structure of Gibberella zeae isolated from wheat in Argentina. Food Addit. Contam. 24:1115-1120.

Reis, E. M. 1988. Quantificação de propágulos de Gibberella zeae no ar através de armadilhas de esporos. Fitopatol. Bras. 13:324-327.

Reis, E. M. 1990. Perithecial formation of Gibberella zeae on senescent stems of grasses under natural conditions. Fitopatol. Bras. 15:52-54

Schaafsma, A. W., Tamburic-Ilincic, L., and Hooker, D. C. 2005. Effect of previous crop, tillage, field size, adjacent crop, and sampling direction on airborne propagules of Gibberella zeae/Fusarium graminearum, Fusarium head blight severity, and deoxynivalenol accumulation in winter wheat. Can J. Plant Pathol. 27:217-224.

Schmale, D. G., III, Ross, S. D., Fetters, T. L., Tallapragada, P., Wood-Jones, A. K., and Dingus, B. 2012. Isolates of Fusarium graminearum collected 40-320 meters above ground level cause Fusarium head blight in wheat and produce trichothecene mycotoxins. Aerobiologia 28:1-11.

Schmale, D. G., III, Shah, D. A., and Bergstrom, G. C. 2005. Spatial patterns of viable spore deposition of Gibberella zeae in wheat fields. Phytopathology 95:472-479.

Schmale, D. G., Wood-Jones, A. K., Cowger, C., Bergstrom, G. C., and Arellano, C. 2011. Trichothecene genotypes of Gibberella zeae from winter wheat fields in the eastern USA. Plant Pathol. 60:909-917.

Seem, R. C. 1984. Disease incidence and severity relationships. Annu. Rev. Phytopathol. 22:133-150.

Shah, D. A., De Wolf, E. D., Paul, P. A., and Madden, L. V. 2014. Predicting Fusarium head blight epidemics with boosted regression trees Phytopathology 104:702-714.

Shah, D. A., Molineros, J. E., Paul, P. A., Willyerd, K. T., Madden, L. V., and De Wolf, E. D. 2013. Predicting Fusarium head blight epidemics with weather-driven pre- and post-anthesis logistic regression models. Phytopathology 103:906-919.

Spolti, P., Guerra, D. S., Badiale-Furlong, E., and Del Ponte, E. M. 2013. Single and sequential applications of metconazole alone or in mixture with pyraclostrobin to improve Fusarium head blight control and wheat yield in Brazil. Trop. Plant Pathol. 38:85-96.

Umpiérrez-Failache, M., Garmendia, G., Pereyra, S., Rodríguez-Haralambides, A., Ward, T. J., and Vero, S. 2013. Regional differences in species composition and toxigenic potential among Fusarium head blight isolates from Uruguay indicate a risk of nivalenol contamination in new wheat production areas. Int. J. Food Microbiol. 166:135-40.

Wilhelm, K. P., and Jones, R. K. 2005. Meso- and microscale patterns of Fusarium head blight in spring wheat fields in Minnesota. Plant Dis. 89:474-479.

Xu, X.-M., Parry, D. W., Edwards, S. G., Cooke, B. M., Doohan, F. M., Maanen, A., Brennan, J. M., Monaghan, S., Moretti, A., Tocco, G., Mule, G., Hornok, L., Giczey, G., Tatnell, J., Nicholson, P., and Ritieni, A. 2004. Relationship between the incidences of ear and spikelet infection of Fusarium ear blight in wheat. Eur. J. Plant Pathol. 110:959-971.

Xu, X.-M., Parry, D. W., Nicholson, P., Thomsett, M. A., Simpson, D., Edwards, S. G., Cooke, B. M., Doohan, F. M., Brennan, J. M., Moretti, A., Tocco, G., Mule, G., Hornok, L., Giczey, G., and Tatnell, J. 2005. Predominance and association of pathogenic fungi causing Fusarium ear blight in wheat in four European countries. Eur. J. Plant Pathol. 112:143-154.

Zadoks, J. C., Chang, T. T., and Konzak, C. F. 1974. A decimal code for the growth stages of cereals. Weed Res. 14:415-421. 